\title{
Calculated Antibiosis of Acute Cholangitis and Cholecystitis
}

\author{
Till Bornscheuer Stefan Schmiedel \\ 1. Department of Medicine, University Hospital Hamburg-Eppendorf, Hamburg, Germany
}

\section{Keywords}

Biliary infection - Acute cholangitis .

Acute cholecystitis - Antimicrobial therapy .

Calculated antimicrobial therapy .

Empirical therapy - Presumptive therapy .

Antibiotic therapy

\section{Summary}

Background: The aim of this article is to present the most recent suggestions for the therapy of acute cholangitis and cholecystitis based on a review of the current literature. Methods: We performed a systematic literature search in the Medline, PubMed, and Google Scholar databases using the keywords mentioned above. This article is strongly influenced by the publication of the Tokyo Guidelines for the management of acute cholangitis and cholecystitis (TG07, TG13) in 2007 and 2013. These were the first practical guidelines targeting diagnosis and treatment of acute cholangitis and cholecystitis. These guidelines are based on the best published evidence and a consensus conference of international experts in the field. Results and Conclusion: Acute cholangitis and acute cholecystitis are common conditions that may result in progressively severe infection and death when not treated appropriately. Beside supportive therapy and antiobstructive measures, therapy with antimicrobial agents is an important component in the management of affected patients. Here, we discuss the use of antimicrobial agents that are suitable for the first-line management of these infections. Empirical therapy depends upon the knowledge of local microbial epidemiology and patient-specific factors affecting the selection of appropriate agents.

\section{Schlüsselwörter}

Gallenwegsinfektion - Akute Cholangitis .

Akute Cholezystitis - Antimikrobielle Therapie .

Kalkulierte antimikrobielle Therapie .

Empirische Therapie - Kalkulierte antibiotische Therapie . Antibiotische Therapie

\section{Zusammenfassung}

Hintergrund: In diesem Artikel sollen aktuelle Empfehlungen zur antimikrobiellen Therapie der akuten Cholangitis und Cholezystitis basierend auf einer Literaturrecherche präsentiert werden. Methoden: Es wurde eine systematische Literaturrecherche der oben angegebenen Schlüsselwörter in den Datenbanken Medline, PubMed und Google Scholar durchgeführt. Der Artikel ist stark beeinflusst von den Veröffentlichungen der "Tokyo Guidelines" zur Behandlung der akuten Cholangitis und Cholezystitis. Hierbei handelte es sich um die ersten konkreten Empfehlungen zur Diagnose und Behandlung der akuten Cholangitis und Cholezystitis basierend auf den Veröffentlichungen zu diesem Thema sowie einer Konsensuskonferenz. Ergebnisse und Schlussfolgerung: Die akute Cholangitis und Cholezystitis sind häufige Erkrankungen, die, wenn nicht adäquat behandelt, zu fortschreitenden schweren Infektionen und Tod führen können. Neben supportiver Therapie und antiobstruktiven Maßnahmen stellt eine antimikrobielle Therapie einen wichtigen Teil der Behandlung bei betroffenen Patienten dar. Die zur initialen Therapie dieser Erkrankungen geeigneten antimikrobiellen Substanzen sollen hier diskutiert werden. Die empirische Therapie basiert dabei auf der Kenntnis der lokalen mikrobiellen Epidemiologie und auf patientenspezifischen Faktoren, welche die Auswahl geeigneter Substanzen beeinflussen.

\section{KARGER \\ Fax +497614520714

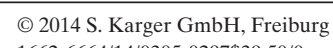

Dr. med. Stefan Schmiedel

1. Department of Medicine

University Hospital Hamburg-Eppendor

Martinistraße 52, 20246 Hamburg, Germany

sschmiedel@bni-hamburg.de 


\section{Introduction}

Patients exhibiting one of the local signs of inflammation, such as Murphy's sign, a mass, pain, jaundice, or tenderness in the right upper quadrant, and systemic inflammation are diagnosed as having acute cholangitis or cholecystitis. Patients with clinical findings that are confirmed by diagnostic imaging are also diagnosed with acute cholangitis or cholecystitis. In these patients, a therapy with appropriate antimicrobial agents is an important component of the management. The goal of antimicrobial therapy in acute cholangitis and cholecystitis is to limit the systemic septic response and local inflammation [1].

Acute cholangitis and cholecystitis are common conditions that may result in progressively severe infection, particularly in debilitated hosts. An appropriate treatment is required in the acute phase. Severe acute cholangitis or cholecystitis may result in early death if appropriate medical care is not provided [2-6]. An attempt to develop a clinical guidance was provided by the Tokyo Guidelines (TG) 2007 in which international standards for diagnostics and severity assessment criteria for acute cholecystitis and cholangitis were defined for the first time [2].

Here, we discuss antimicrobial agents that are suitable for the first-line management of these infections. We focus primarily on empirical therapy (presumptive therapy), which is provided before the infecting isolates are identified. Such therapy depends upon the knowledge of local microbial epidemiology and patient-specific factors affecting the selection of appropriate agents [3].

\section{Etiology and Pathogenesis}

Acute biliary infections are systemic infectious diseases requiring prompt treatment. Acute cholangitis and cholecystitis are conditions with acute inflammation and infection of the biliary system, which are often accompanied by chills, right upper quadrant pain, and jaundice (Charcot trias); sometimes, lethargy, confusion, and shock are additionally present. In many cases, biliary obstruction plays a leading role in the pathogenesis and is sometimes complicated by abscess formation [7]. Frequent causes of biliary obstruction are choledocholithiasis, benign biliary stenosis, strictures after biliary interventions as well as after ischemic (SSC) or sterile inflammation (PSC), and stenosis caused by malignant tumors. An overview of common underlying causes for biliary obstruction and inflammation is given in table 1 [8]. Quite often, acute cholangitis and cholecystitis are due to biliary obstruction and ascending infection of the bile. In the vast majority of cases, bacteria are the causative infective organisms for acute biliary infections. In some populations, immunosuppressed viral (cytomegalovirus) or parasitic agents (cryptosporidia, isospora) [9] may be found. This article fo-
Table 1. Etiology of acute cholangitis (modified according to $[8])$

Table 2. Microorganisms isolated from bile cultures among patients with acute biliary infections (modified according to $[10,11])$

Table 3. Common isolates from patients with bacteremic biliary tract infections (modified according to $[10,11])$

cuses on the majority of cases, which are due to bacterial infections.

The bacteria commonly found in biliary tract infections are well known. Most of these bacteria originate from the upper and lower intestine (table 2, 3) [10, 11]. The bile of healthy subjects is generally aseptic. However, bile cultures are posi- 
tive for microorganisms in $16 \%$ of the patients, in $72 \%$ of those with acute cholangitis, in $44 \%$ in chronic cholangitis patients, and in $50 \%$ of those with biliary obstruction [10-12].

Table 4.Diagnostic criteria for acute cholangitis (TG13) (modified according to [12] $)^{\mathrm{a}}$

\begin{tabular}{l} 
A. Systemic inflammation \\
Fever and/or chills \\
Laboratory evidence of inflammation \\
\hline B. Cholestasis \\
Jaundice \\
Abnormal liver function tests \\
\hline C. Imaging \\
Biliary dilatation \\
Evidence of the etiology on imaging (obstruction, stricture, stone, \\
stent, empyema etc.)
\end{tabular}

aSuspected diagnosis: One item in A and one item in either B or C.

Table 5.Severity assessment criteria for acute cholangitis/cholecystitis (TG13) (modified according to [12])

\section{Grade I}

Grade I (mild) acute cholangitis/cholecystitis does not meet the criteria of Grade III (severe) or Grade II (moderate) acute cholangitis

\section{Grade II}

Grade II (moderate) acute cholangitis/cholecystitis at initial diagnosis is associated with any two of the following conditions: Abnormal WBC count $\left(>12,000 / \mathrm{mm}^{3},<4,000 / \mathrm{mm}^{3}\right)$

High fever $\left(>39.0^{\circ} \mathrm{C}\right)$

Age ( $>75$ years)

Hyperbilirubinemia (total bilirubin $>5 \mathrm{mg} / \mathrm{dl}$ )

\section{Grade III}

Grade III (severe) acute cholangitis/cholecystitis is associated with cardiac, renal, neurological, respiratory, hepatic, and hematological dysfunction

\section{Management}

Patients suspected of having acute cholangitis or cholecystitis should be admitted to a hospital for further evaluation. An early assessment of disease severity is essential for all of these patients (table 4, 5) [1].

\section{Patient Assessment}

All patients with suspected or proven cholangitis or cholecystitis (table 6) should be evaluated and grouped according to the TG13 severity assessment criteria (table 7) [1,2].

Early diagnosis, early biliary drainage or treatment for etiology, and antimicrobial administration are fundamental for the treatment for acute cholangitis/cholecystitis not only in severe and moderate but also in mild disease.

Therefore, it is recommended that patients with acute cholangitis/cholecystitis who do not respond to the initial medical treatment (general supportive care and antimicrobial therapy) undergo early biliary drainage or treatment for etiology, and, in the case of cholecystitis, surgical therapy.

\section{Diagnostic Procedures}

Identifying the causative organism is an essential step in the management of acute biliary infections.

Blood cultures are not routinely recommended for non-severe acute cholecystitis. The Surgical Infection Society and the Infectious Diseases Society of America (SIS-NA/IDSA) guidelines from 2010 advise against routine blood cultures for communityacquired intra-abdominal infections, since the results do not change the management and outcomes [13, 14]. Positive rates of blood cultures among patients with acute cholangitis ranged from 21 to $71 \%$ [15]. However, we would recommend taking cultures as it is simple, easy to take, and might mandate changes in therapy.

Table 6.Antimicrobial recommendations for acute biliary infections (TG13) (modified according to [1])

\begin{tabular}{|c|c|c|c|c|}
\hline & \multicolumn{4}{|c|}{ Cholangitis and cholecystitis, severity } \\
\hline & grade I & grade I & grade III & healthcare-associated \\
\hline $\begin{array}{l}\text { Anti-microbial } \\
\text { agent }\end{array}$ & $\begin{array}{l}\text { ampicillin/sulbactam is not } \\
\text { recommended without } \\
\text { an aminoglycoside; } \\
\text { cefazolin, cefotiam, } \\
\text { cefuroxime, ceftriaxone, } \\
\text { cefotaxim } \pm \text { metronidazole }\end{array}$ & $\begin{array}{l}\text { piperacillin/tacobactam; } \\
\text { ceftriaxone, cefotaxim, } \\
\text { cefepim, ceftacidim; } \\
\text { ciprofloxacin, levofloxacin } \\
\pm \text { metronidazole, moxifloxacin } \\
\pm \text { metronidazole; impinem/ } \\
\text { celastin, meropenem } \pm \text { vanco- } \\
\text { mycin, linezolid, daptomycin }\end{array}$ & $\begin{array}{l}\text { piperacillin/tacobactam } \\
\pm \text { vancomycin, linezolid, } \\
\text { daptomycin; ceftriaxone, } \\
\text { cefotaxim, cefepim, ceftaci- } \\
\text { dim, metronidazole } \pm \text { vanco- } \\
\text { mycin, linezolid, daptomy- } \\
\text { cin; impinem/celastin, } \\
\text { meropenem } \pm \text { vancomycin, } \\
\text { linezolid, daptomycin; } \\
\text { impinem/celastin, } \\
\text { meropenem } \pm \text { vancomycin, } \\
\text { linezolid, daptomycin }\end{array}$ & $\begin{array}{l}\text { piperacillin/tacobactam } \\
\pm \text { vancomycin, linezolid, } \\
\text { daptomycin; cefepim, } \\
\text { ceftacidim } \pm \text { metronidazole } \\
\pm \text { vancomycin, linezolid, } \\
\text { daptomycin; imipenem/ } \\
\text { cilastin, meropenem } \\
\pm \text { vancomycin, linezolid, } \\
\text { daptomycin }\end{array}$ \\
\hline
\end{tabular}


Table 7. Agents and regimens that may be used for the initial empiric treatment of biliary infection in adults (SIS/IDSA 2010) (modified according to [14])

\begin{tabular}{|c|c|}
\hline Infection & Regimen \\
\hline $\begin{array}{l}\text { Community-acquired acute cholecystitis of } \\
\text { mild-to-moderate severity }\end{array}$ & cefazolin, cefuroxime, or ceftriaxone \\
\hline $\begin{array}{l}\text { Community-acquired acute cholecystitis } \\
\text { of severe physiologic disturbance, } \\
\text { advanced age, or immunocompromised } \\
\text { state }\end{array}$ & $\begin{array}{l}\text { imipenem-cilastatin, meropenem, doripenem, } \\
\text { piperacillin-tazobactam, ciprofloxacin, } \\
\text { levofloxacin, or cefepime, each in combination } \\
\text { with metronidazole }\end{array}$ \\
\hline $\begin{array}{l}\text { Acute cholangitis following bilio-enteric } \\
\text { anastamosis of any severity }\end{array}$ & $\begin{array}{l}\text { imipenem-cilastatin, meropenem, doripenem, } \\
\text { piperacillin-tazobactam, ciprofloxacin, } \\
\text { evofloxacin, or cefepime, each in combination } \\
\text { with metronidazole }\end{array}$ \\
\hline $\begin{array}{l}\text { Health care-associated biliary infection } \\
\text { of any severity }\end{array}$ & $\begin{array}{l}\text { imipenem-cilastatin, meropenem, doripenem, } \\
\text { piperacillin-tazobactam, ciprofloxacin, } \\
\text { levofloxacin, or cefepime, each in combination } \\
\text { with metronidazole, vancomycin added to each } \\
\text { regimen }\end{array}$ \\
\hline
\end{tabular}

Bile cultures should be obtained at the beginning of any surgical or endoscopic procedure. Cultures of bile and tissue should be performed when perforation, emphysematous changes, or necrosis of gallbladder are noted during cholecystectomy. Positive rates of bile cultures range from 59 to $93 \%$ for acute cholangitis and from 29 to $67 \%$ for acute cholecystitis. Table 2 shows common microbial isolates from bile cultures among patients with acute biliary infections [11-15].

In patients with confirmed cholangitis or cholecystitis, management consists of three cornerstones: i) supportive care, ii) empiric antibiotic coverage, and iii) biliary drainage in acute cholangitis and final surgical treatment for acute cholecystitis.

Supportive care consists of fluid reconstitution, pain management, and management of complications $[1,14,16]$. For biliary drainage in acute cholangitis, endoscopic retrograde cholangiopancreatography (ERCP) is the treatment of choice. The optimal point of time depends on the severity of illness [17]. Early laparoscopic cholecystectomy is the standard definitive management for acute calculous cholecystitis [18].

\section{Antimicrobial Therapy for Cholangitis and Cholecystitis}

The rationale for antimicrobial therapy is to prevent both a systemic septic response and a local inflammation. Furthermore, it should prevent infections after surgical procedures as well as intrahepatic abscess formation. The selection of antibiotics is essential since inadequate initial antibiotic therapy is an independent predictor of mortality [19].

Before choosing an antimicrobial therapy several points should be considered: suspected pathogens, local epidemiology and resistance patterns, pharmacodynamics and pharmacokinetics, the history of antimicrobial usage, severity of illness, nosocomial or community-acquired nature of infection, and allergies or adverse reactions [1].
The antimicrobial therapy should be initiated as soon as the diagnosis of cholangitis or cholecystitis is suspected. While antibiotics should be administered immediately for patients with suspected septic shock, up to 4 h could be spent for obtaining definitive diagnosis in other patients. In all patients, antimicrobial therapy should be started before any invasive procedure $[1,2,10,17,19,20]$.

To this day, only few randomized controlled trials have evaluated the effect of antimicrobial therapy on acute cholangitis and/or cholecystitis [1]. All these studies, except one from 2012, are outdated and were conducted in part with antibiotics no longer used in clinical practice. Comparisons of these trials are quite complex as they differ in tested antibiotics, study design, and tested population. However, all of them demonstrated that the chosen antibiotics had a comparable effectiveness and usefulness with ampicillin and an aminoglycoside, which was considered to be the standard regime for acute cholecystitis in the 1980s [21]. The nowadays widely used penicillin and $\beta$-lactamase inhibitors, the carbapenems, and the third- and fourth-generation cephalosporins were mainly not tested in these randomized controlled trials. In spite of this, the TG for antimicrobial therapy for acute cholangitis and cholecystitis (TG13) updated in 2013 and the SIS/ IDSA 2010 define recommendations for antimicrobial treatment depending on severity of illness and the community-acquired and healthcare-associated nature of biliary infections $[1,14]$. Tables 6 and 7 summarize antimicrobial recommendations of TG13 and SIS/IDSA for acute community-acquired cholangitis.

Several antibiotic regimes based on different antimicrobial classes seem to be reasonable. For cholecystitis and cholangitis with mild-to-moderate severity, the TG13 guidelines include penicillin-, cephalosporin-, carbapenem-, monobactam-, and, with limitations, fluorchinolone-based therapy regimes. In contrast, the SIS/IDSA guidelines for mild-to-moderate cholangitis/cholecystitis recommend only cephalosporin- 
based regimes. The use of ampicillin/sulbactam as a monotherapy is no longer recommended because of high rates of resistance to this agent among community-acquired Escherichia coli [14]. In face of the increasing number of multidrugresistant Gram-negative bacteria (MDRGN bacteria) and Klebsiella in the community, it should be noted that these organisms are not sufficiently covered by cephalosporins, penicillin derivatives, or fluorchinolones [21, 22]. If more than 10$20 \%$ of isolates in the community are resistant, empiric therapy should cover these resistant organisms until susceptibility data are available [14].

One randomized prospective trial from 2012 evaluated the effect of preoperative antibiotic treatment in 84 patients who underwent delayed cholecystectomy. In this study, there were no statistically significant differences regarding duration of hospitalization and rate of readmission between patients who received antibiotic treatment with amoxicillin/clavulanic acid until discharge and those who received no antibiotic treatment [23]. However, it should be noted that the chosen antibiotics are no longer recommended as monotherapy, and both the TG from 2013 and the guidelines by the SIS/IDSA still recommend the initiation of antimicrobial therapy when infection is suspected. The data of one recently published paper justify the use of broad-spectrum antimicrobial regimens for the empirical treatment of acute cholangitis in patients undergoing stent therapy to minimize the risk of a therapy failure before antimicrobial susceptibility testing is available [24].

For grade III cholangitis and cholecystitis, both guidelines recommend antimicrobial regimes with antipseudomonal activity for initial therapy as Pseudomonas aeruginosa could be detected in approximately $20 \%$ of the patients in recent studies [15, 22]. Additionally, Enterococcus sp. is an important pathogen in patients with grade III community-acquired cholangitis or cholecystitis. Therefore, vancomycin should be added in all cases of severe acute cholangitis or cholecystitis to cover Enterococcus sp. [1-3, 14].

For all patients with a biliary-enteric anastomosis, coverage of anaerobic pathogens is recommended irrespective of the severity of illness $[1,14]$.

Treatment of healthcare-associated biliary infection should be based on an empirical antimicrobial treatment that includes agents with antipseudomonal activity. The TG13 expand this recommendation to include empirical coverage against multidrug-resistant bacteria [1].

Once results of susceptibility testing become available, treatment should be narrowed.

So far, no well-designed and randomized controlled trials have evaluated the optimal treatment duration for community-acquired and healthcare-associated cholangitis or cholecystitis. One observational study from 2013 showed that antimicrobial therapy for more than 4 days after urgent cholecystectomy was not associated with fewer surgical site infections than antimicrobial treatment for up to 4 days [25]. In patients with mild cholecystitis, the TG13 recommend to stop antimicrobial therapy within $24 \mathrm{~h}$ after cholecystectomy is performed. In grade I-III cholangitis as well as in cholecystitis before definitive surgical therapy, the antimicrobial therapy should be continued for 4-7 days. If bacteremia with Grampositive cocci such as Enterococcus sp. or Streptococcus spp. is present, a minimum duration of 2 weeks is recommended in some publications and guidelines, though the rationale remains unclear $[1,10,25]$. We believe that a shorter course of treatment is feasible when sufficient antibiotic bioavailability is granted and when the antibiotic is tailored according to pathogen susceptibility.

Patients who tolerate oral food intake may be treated with oral antimicrobial therapy [26]. The selection of oral antimicrobial agents should be guided by susceptibility patterns of the organisms identified $[1,7]$.

\section{Summary and Recommendations}

Current guidelines for the management of acute cholangitis and cholecystitis recommend the following procedures. Due to a lack of evidence from well-designed studies all current recommendations dealing with antimicrobial therapy are mainly based on expert opinion.

- Patients suspected of having acute cholangitis or cholecystitis should be admitted to a hospital. A clinical assessment should be performed for severity grading.

- Blood culture should be taken before initiating empiric antibiotic therapy and, whenever feasible, bile cultures should be taken.

- Empiric, antibiotic therapy tailored according to clinical and epidemiological findings must get initiated early $(<4$ h).

- Adjunctive therapy (fluid management, pain management, antipyretics) should be administered.

- Drainage therapy must get offered early in the course of illness, preferably by means of ERCP. For cholecystitis, definitive surgical therapy must be evaluated from the beginning.

- In mild cholecystitis, antibiotic therapy may be stopped $24 \mathrm{~h}$ after surgery.

- Empirical antibiotics should be tailored after the results of susceptibility testing become available.

- Antimicrobial therapy should be given for 4-7 days.

\section{Disclosure Statement}

No financial disclosures or conflicts of interest. 


\section{References}

1 Gomi H, Solomkin JS, Takada T, Strasberg SM, Pitt HA, Yoshida M, Kusachi S, Mayumi T, Miura F, Kiriyama S, Yokoe M, Kimura Y, Higuchi R, Windsor JA, Dervenis C, Liau KH, Kim MH; Tokyo Guideline Revision Committee: TG13 antimicrobial therapy for acute cholangitis and cholecystitis. J Hepatobiliary Pancreat Sci 2013;20:60-70.

$\checkmark 2$ Tokyo Guidelines for the management of acute cholangitis and cholecystitis. Proceedings of a consensus meeting, April 2006, Tokyo, Japan. J Hepatobiliary Pancreat Surg 2007;14:1-121.

- 3 Schukfeh N, Doerner JM, Heintschel von Heinegg E, Steinmann J, Metzelder ML, Kathemann S, Hoyer PF, Paul A, Gerner P: Spectrum of pathogens in native liver, bile and blood during pediatric liver transplantation. Pediatr Transplant 2014;18:266-271.

4 Bencini L, Tommasi C, Manetti R, Farsi M: Modern approach to cholecysto-choledocholithiasis. World J Gastrointest Endosc 2014;6:32-40.

$\checkmark 5$ Sharma BC, Kumar R, Agarwal N, Sarin SK: Endoscopic biliary drainage by nasobiliary drain or by stent placement in patients with acute cholangitis. Endoscopy 2005;37:439-443.

6 Salek J, Livote E, Sideridis K, Bank S: Analysis of risk factors predictive of early mortality and urgent ERCP in acute cholangitis. J Clin Gastroenterol 2009;43:171-175.

7 Lai EC: Management of severe acute cholangitis. Br J Surg 1990;77:604-605.

8 Eskelinen M, Ikonen J, Lipponen P: Diagnostic approaches in acute cholecystitis; a prospective study of 1333 patients with acute abdominal pain. Theor Surg 1993;8:15-20.

9 Cello JP: AIDS-related biliary tract disease. Gastrointest Endosc Clin N Am 1998;8:963.

10 Tanaka A, Takada T, Kawarada Y, et al: Antimicrobial therapy for acute cholangitis: Tokyo Guidelines. J Hepatobiliary Pancreat Surg 2007;14:59-61.
11 Csendes A, Mitru N, Maluenda F, Diaz J, Burdiles $\mathrm{P}$, Csendes P, Pinones E: Counts of bacteria and pyocites of choledochal bile in controls and in patients with gallstones or common bile duct stones with or without acute cholangitis. Hepatogastroenterology 1996;43:800-806.

12 Lee JK, Park CW, Lee SH, Kang HW, Kwon JH, Kim JH, Lim YJ, Kim ES, Koh MS, Lee JH: Updates in bacteriological epidemiology of community-acquired severe acute cholangitis and the effectiveness of metronidazole added routinely to the first-line antimicrobial regimen. J Infect Chemother 2013;19:1029-1034.

13 Sun G, Han L, Yang Y, Linghu E, Li W, Cai F, Kong J, Wang X, Meng J, Du H, Wang H, Huang Q, Hyder Q, Zhang X: Comparison of two editions of Tokyo guidelines for the management of acute cholangitis. $\mathrm{J}$ Hepatobiliary Pancreat Sci 2014;21:113-119.

14 Solomkin JS, Mazuski JE, Bradley JS, et al: Diagnosis and management of complicated intra-abdominal infection in adults and children: guidelines by the Surgical Infection Society and the Infectious Diseases Society of America. Clin Infect Dis 2010; 50:133-164.

15 Salvador V, Lozada M, Consunji R: Microbiology and antibiotic susceptibility of organisms in bile cultures from patients with and without cholangitis at an Asian Academic Medical Center. Surg Infect 2011;12:105-111.

16 Kiriyama S, Takada T, Strasberg SM, et al: New diagnostic criteria and severity assessment of acute cholangitis in revised Tokyo guidelines. J Hepatobiliary Pancreat Sci 2012;19:548-556.

17 Dasari BVM, Tan C, Gurusamy K, Martin DJ, Kirk G, McKie L, Diamond T, Taylor MA: Surgical versus endoscopic treatment of bile duct stones. Cochrane Database Syst Rev 2013;9:CD003327.
8 Gurusamy K, Davidson C, Gluud C, Davidson BR: Early versus delayed laparoscopic cholecystectomy for people with acute cholecystitis. Cochrane Database Syst Rev 2013;6:CD005440.

19 Yoshida M, Takada T, Kawarada Y, et al: Antimicrobial therapy for acute cholecystitis: Tokyo Guidelines. J Hepatobiliary Pancreat Surg 2007;14:83-90.

20 Dellinger RP, Levy MM, Carlet JM, et al: Surviving Sepsis Campaign: international guidelines for management of severe sepsis and septic shock: 2008. Crit Care Med 2008;36:296-327.

21 Fuks D, Cossé C, Régimbeau J-M: Antibiotic therapy in acute calculous cholecystitis. J Visc Surg 2013;150:3-8.

22 Sung Y, Lee J, Lee K, Lee K, Kang C-I: The clinical epidemiology and outcomes of bacteremic biliary tract infections caused by antimicrobial-resistant pathogens. Am J Gastroenterol 2012;107:473-483.

23 Mazeh H, Mizrahi I, Dior U, Simanovsky N, Shapiro M, Freund HR, Eid A: Role of antibiotic therapy in mild acute calculus cholecystitis: a prospective randomized controlled trial. World J Surg 2012;36:1750-1759.

24 Schneider J, DeWaha P, Hapfelmeier A, Feihl, S, Römmler, F, Schlag C, Algül H, Schmid R, Wantia $\mathrm{N}$, Huber W, Weber A: Risk factors for increased antimicrobial resistance: a retrospective analysis of 309 acute cholangitis episodes. J Antimicrob Chemother 2014;69:519-525.

25 Rodríguez-Sanjuán J, Casella G, Antolín F, et al: How long is antibiotic therapy necessary after urgent cholecystectomy for acute cholecystitis? J Gastrointest Surg 2013;17:1947-1952.

26 Solomkin J, Dellinger E, Bohnen J, Rostein O: The role of oral antimicrobials for the management of intra-abdominal infections. New Horiz 1998;6:S4652. 